\title{
Karbonmonoksit intoksikasyonundan organ donasyonuna; ağır pulmoner hasarda organ koruyucu mekanik ventilasyon
}

\author{
Mehtap PEHLIVANLAR \\ KÜÇÜK ${ }^{1}$ \\ Nazan KÖYLÜ ILKAYA ${ }^{1}$ \\ Çağatay Erman ÖZTÜRK ${ }^{1}$ \\ Halil CEBECi ${ }^{1}$ \\ Davut AYDIN ${ }^{1}$ \\ Fatma ÜLGER ${ }^{1}$
}

\footnotetext{
${ }^{1}$ Ondokuz Mayıs Üniversitesi Tıp Fakültesi, Anesteziyoloji ve Reanimasyon Anabilim Dalı, Yoğun Bakım Bilim Dalı, Samsun, Türkiye

${ }^{1}$ Division of Intensive Care, Department of Anesthesiology and Reanimation, Faculty of Medicine, Ondokuz Mayis University, Samsun, Turkey
}

\section{ÖZET}

Karbonmonoksit intoksikasyonundan organ donasyonuna; ağır pulmoner hasarda organ koruyucu mekanik ventilasyon

Karbonmonoksit (CO) intoksikasyonu sonrası yoğun bakım ihtiyacı olan kritik hastalarda organ donasyonu soru işaretleri taşıyan bir konudur. Yirmi altı yaşında kadın hasta, tüplü şofbenle su ısıtılan (\%70 bütan ve \%30 propan karışımı) banyoda 20 dakika geçirdikten sonra baygın vaziyette bulunmuştur. Glasgow koma skalası (GKS) 3 olan hastanın beyin bilgisayarlı tomografi (BT)'sinde ventriküler sistem silinmiş, beyaz-gri cevher ayrımı kaybolmuş ve fissürler silinmiş olarak izlendi. Torax BT'sinde her iki akciğer bazal ve posteriorlarda hava bronkogramları gösteren konsolide alanlar ve diğer alanlarda yaygın buzlu cam dansiteleri izlendi. Bilinç durumunda düzelme olmayan hastada apne testi, nörolojik muayene ve BT anjiyoyla beyinde kan akımı olmadığı ve beyin ölümü tanısı doğrulanmıştır. Hasta yatışının 2. gününde yakınlarının da onamıyla böbrek ve karaciğer donörü olmuştur. Karbonmonoksit zehirlenmelerinde yine yüksek konsantrasyonlarda oksijen verilebilmesi ve kapalı alveollerin açılmasına (recruitment) olanak sağlayabileceği için kullanımı avantajılı olabilir. CO'ya maruz kalmış donörlerden yapılan başarılı böbrek, kalp, akciğer, karaciğer ve pankreas nakilleri raporlanmıştır. Karbonmonoksit intoksikasyonunda, organ koruyucu bakımın iyi yapıldığı beyin ölümü olgularının organ bekleyen hastalar için transplantasyona uygun olabileceğini ve literatürde başarısız olguların da olmasına rağmen kesin kontrendikasyon olmadığını göstermektedir.

Anahtar kelimeler: APRV; beyin ölümü; organ nakli; karbonmonoksit intoksikasyonu

\section{ABSTRACT}

From carbonmonoxide intoxication to organ donation; organ protective mechanic ventilation in severe pulmonary damage

Organ donation is a matter of concern in critically ill patients who need intensive care after carbonmonoxide (CO) intoxication. A 26-year-old female patient was unconscious after having spent 20 minutes in the bathroom with a water heater $(70 \%$ butane and $30 \%$ propane mixture). In the CT of the patient with Glasgow

\section{Yazışma Adresi (Address for Correspondence)}

Dr. Mehtap PEHLIVANLAR KÜÇÜK

Ondokuz Mayıs Üniversitesi Tıp Fakültesi, Anesteziyoloji ve Reanimasyon Anabilim Dalı, Yoğun Bakım Bilim Dalı, SAMSUN - TÜRKIYE

e-mail: mehtap_phlvnlr@hotmail.com 
Coma Scale (GCS) 3, ventricular system was erased, white-gray matter separation was lost and fissures were observed as erased. Torax CT showed conspicuous areas showing air bronchograms in both lung bases and posterior areas and diffuse frosted glass densities in other areas. In a patient with no improvement in consciousness; apnea test, neurological examination and CT angiography showed that there was no blood flow in the brain and brain death was confirmed. On the second day of hospitalization, the relatives gave their approval for the donation. It may also be advantageous to use oxygen at high concentrations in carbonmonoxide poisoning as it may allow recruitment of closed alveoli. Successful kidney, heart, lung, liver and pancreas transplants from donors exposed to CO have been reported. Carbonmonoxide intoxication may be appropriate for transplantation for patients who are waiting for organs of brain death cases where the organ preservation is well done. Although carbonmonoxide intoxication has failed in the literature, it shows that there is no definite contraindication.

Key words: APRV; brain death; carbonmonoxide intoxication; organ donation

\section{Giriş}

Karbonmonoksit (CO) renksiz, kokusuz, tatsız, irritan olmayan bir gazdır. Karbon kaynağı olan yakıtların iyi yanmaması sonucu ortaya çıkar ve mortaliteyle sonuçlanabilen zehirlenmelere neden olabilir $(1,2)$. Zehirlenme sonucu inhalasyonla alınan $\mathrm{CO}$ gazı alveoler kapiller memrandan geçer ve hemoglobinle bağlandığı intravasküler alana geçer. CO'nun çoğu eritrositlerde biriktikten sonra kararlı hale gelir. CO'nun hemoglobine afinitesi oksijene göre 220 kat daha fazladır. Bu sebeple hemoglobine afinitesi oksijenle kompetitif olarak ve kararlı şekilde bağlanarak molekülün oksijen taşıma kapasitesini etkiler. Oksijenin taşınma ve dokulara bırakılmasını engeller. CO'nun kardiyak miyoglobine afinitesi de oldukça yüksektir, bu nedenle erken dönemde hipoksiye bağlı miyokardiyal depresyon ve iskemiye bağlı aritmiler gelişebilir (2-4).

CO intoksikasyonlarında çoklu organ tutulumları ve sistem yetmezlikleri görülür. Akciğer grafisi sıklıkla normaldir ancak nadiren buzlu cam görüntüsü, perihiler dolgunluk, ya da intraalveolar ödem izlenebilir. Bu hastalar solunum yetmezliği açısından yakından izlenmelidir. Nadir de olsa mekanik ventilasyon ve yoğun bakım desteği ihtiyacı olabilir. Ciddi intoksikasyonlarda şuur kapanmasına neden olabilecek beyin ödemi görülebilirken, tipik beyin bilgisayarlı tomografi (BBT)'si bulgusu bazal ganglionlarda fokal hipodens lezyonlardır. Bu bulgu özellikle globus palliduslarda simetrik dansite azalmasıdır $(2,3)$. CO intoksikasyonu sonrası yoğun bakım ihtiyacı olan kritik hastalarda organ donasyonu soru işaretleri taşıyan bir konudur. Literatürde başarılı transplantasyon yapılmış olgular olmakla beraber başarısız deneyimler de mevcuttur (5-7). Bu süreçte organ koruyucu destek tedavilerin uygulanması çok önemlidir. Nadir görülen ciddi pulmoner tutulumlu olgularda yeni mekanik ventilasyon stratejileriyle yüksek oksijen konsantrasyonları sağlanabilir. CO intoksikasyonu sonrası yoğun bakım ünitemizde izlenen ve organ vericisi olan 26 yaşında kadın hasta literatür eşliğinde sunulmuştur. Karbonmonoksit intoksikasyonunda, organ koruyucu bakımın iyi yapıldığında beyin ölümü olgularının organ bekleyen hastalar için transplantasyona uygun olabileceğini ve literatürde başarısız olguların da olmasına rağmen kesin kontrendikasyon olmadığını göstermektedir.

\section{OLGU SUNUMU}

Yirmi altı yaşında kadın hasta, tüplü şofbenle su ısıtılan (\%70 bütan ve \%30 propan karışımı) banyoda 20 dakika geçirdikten sonra baygın vaziyette bulunmuştur. Entübe halde, GKS: 3, pupiller fiks dilateyken ilk bakılan karboksihemoglobin $(\mathrm{COHb})$ $\% 67$, kontrolü \%33.9 olarak değerlendirilmiştir. Hastanın acil servisimizde bakılan en kötü kan gazında $\mathrm{pH}: 7.19, \mathrm{pCO}_{2}: 43.5 \mathrm{mmHg}, \mathrm{pO}_{2}: 490 \mathrm{mmHg}$, $\mathrm{HCO}_{3}: 15.4 \mathrm{mEq} / \mathrm{L}, \mathrm{BE}:-11$ ve $\mathrm{COHb}: \% 27.1$ (N: 0.5 2.5) saptanmıştır. Kötü hemodinami, derin koma ve ağır ARDS tablosu nedeniyle (il içerisinde hiperbarik oksijen tedavisi imkanı yoktur) hastanın hiperbarik oksijen için sevki planlanamamıştır. Hasta takibi için yoğun bakım ünitemize devralınmıştır. Genel durumu kötü, şuuru koma, GKS: 3 olan hastanın santal sinir sistemi değerlendirilmesi için çekilen BBT'sinde ventriküler sistem silinmiş, beyaz-gri cevher ayrımı kaybolmuş ve fissürler silinmiş olarak izlenmektedir. Çekilen Torax BT'sinde her iki akciğer bazal ve posteriorlarda hava bronkogramları gösteren konsolide alanlar ve diğer alanlarda yaygın buzlu cam dansiteleri izlendi (Resim 1). Servisimize ilk kabulündeki biyokimyasal değerleri Na: $167 \mathrm{mEq} / \mathrm{L}, \mathrm{K}: 2.7 \mathrm{mEq} / \mathrm{L}$, glukoz: $161 \mathrm{mg} / \mathrm{dL}$, kreatin $0.96 \mathrm{mg} / \mathrm{dL}, \mathrm{BUN}: 9.7 \mathrm{mg} /$ dL, hemoglobin: $8 \mathrm{~g} / \mathrm{dL}, \mathrm{COHb}$ \%20.9, ölçülmüştür. Hipotansif seyreden hastaya (OKB $<65 \mathrm{mmHg}$ ) hemodinamik instabilite nedeniyle dopamin infüzyonu $(1 \mu \mathrm{g} / \mathrm{kg} / \mathrm{dk})$ başlanmıştır. Ciddi beyin ödemi nedeniyle mannitol 6x100 mg IV başlandı. Mekanik ventilatörde airway pressure releasing ventilation (APRV) modda (FiO2: \%100, Phigh: $20 \mathrm{cmH}_{2}$ 0, Plow: 0 


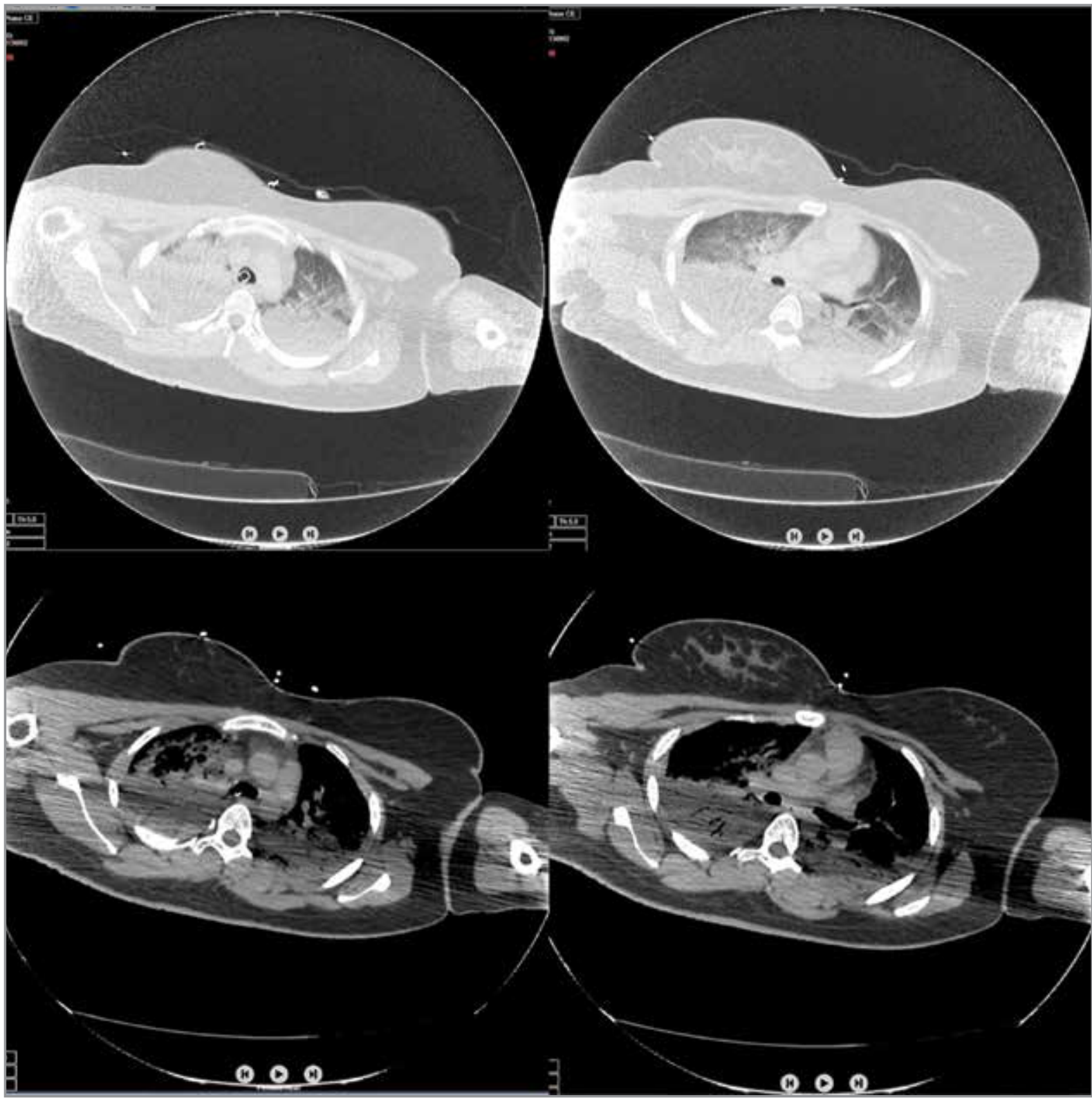

Resim 1. Toraks BT kesitleri.

$\mathrm{cmH}_{2} 0$, Thigh: $4 \mathrm{sn}$, Tlow: $\left.0.8 \mathrm{sn}\right)$ takip edilen hastada 2 saat sonra oksijenizasyonda belirgin iyileşme, kan gazında düzelme, $\mathrm{COHb}$ 'de normalizasyon $(\mathrm{COHb}$ : $\% 0.3$ ) ve kontrol APAC grafisinde belirgin düzelme sağlanmıştır (Resim 2). Bilinç durumunda düzelme olmayan hastada apne testi, nörolojik muayene ve BT anjiyoyla beyinde kan akımı olmadığı ve beyin ölümü tanısı doğrulanmıştır. Hasta yatışının 2. gününde yakınlarının da onamıyla böbrek ve karaciğer donörü olmuştur.

\section{TARTIŞMA}

CO renksiz, kokusuz ve oldukça toksik bir gaz olup dünya çapında zehirlenmeye bağlı ölümlerin önde gelen sebeplerindendir. CO'nun hemoglobine afinitesi oksijene göre 200 kat fazladır, bu sebeple CO intoksikasyonunda dokulara oksijen sunumu azalır, oksihemoglobin disosiasyon eğrisi sola kayar. CO miyoglobine güçlü bağlanır, mitokondrilere oksijen sunumu azalır bu sebeple beyin, kalp, böbrek, iskelet kası, deri, periferal sinir gibi hemen hemen bütün 


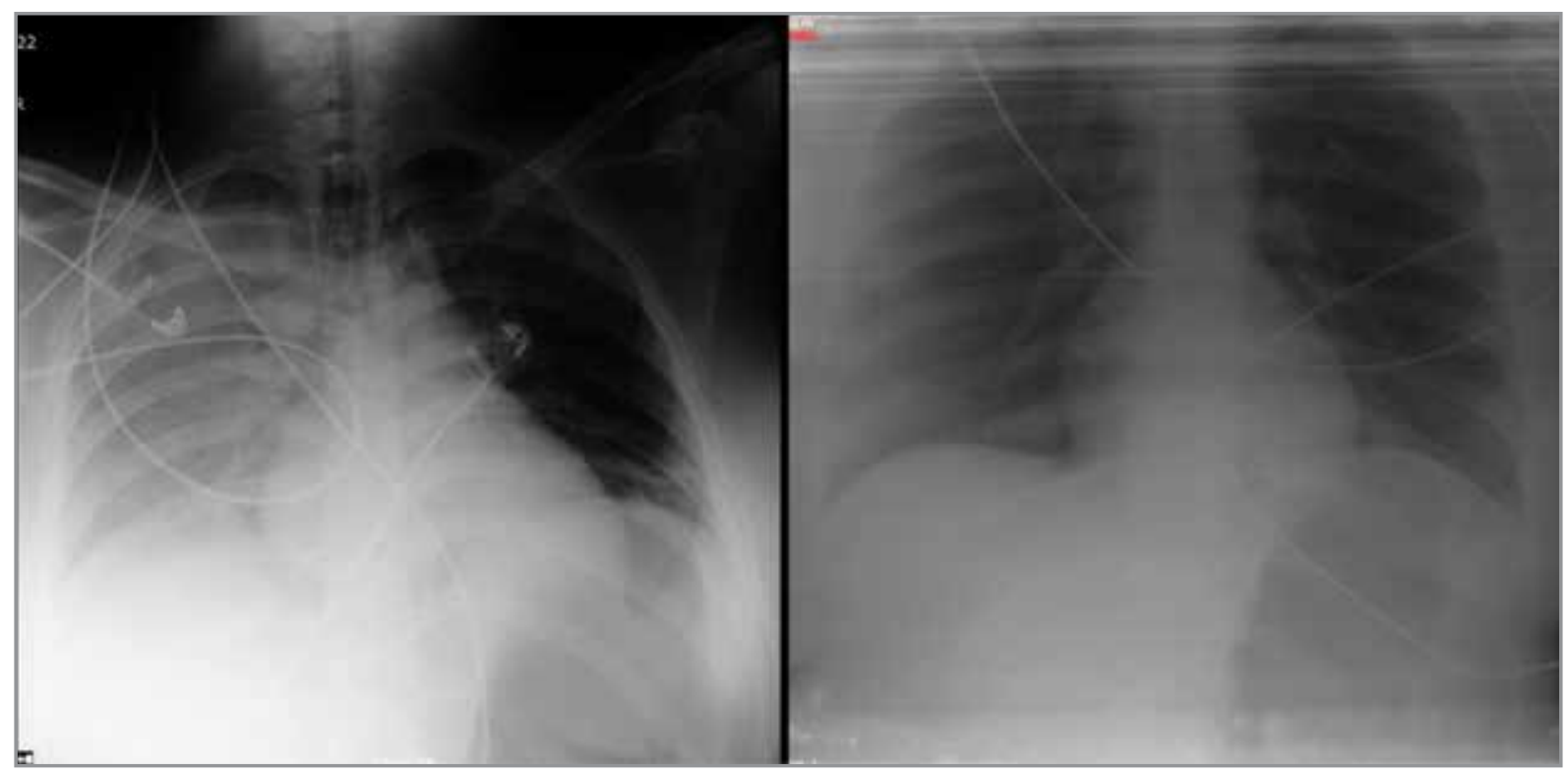

Resim 2. Başvuru anındaki ve 24 saat sonra kontrol APAC grafi görüntüleri.

organları etkileyebilen sıklıkla kötü prognozlu bir durum ortaya çıkar $(6,7)$. Genellikle akciğer grafisi normaldir ancak nadiren olgumuzdaki gibi buzlu cam görüntüsü, perihiler dolgunluk, ya da intraalveolar ödem bulguları görülebilir ve bunlar kötü prognozu gösterir. "Airway pressure release ventilation (APRV)" metoduyla uygulanan mekanik ventilasyon kapiller kaçağa bağlı interstisyel ödem tedavisinde önemli bir mekanik ventilasyon stratejisi olarak akılda tutulabilir (8). APRV devamlı pozitif hava yolu basıncı (CPAP)'nın iki farklı değeri arasında solunmasını sağlayan ve her seviyede spontan solunum eforu olduğunda buna izin veren bir ventilasyon modudur. APRV hala oksijenizasyonun oldukça zor olduğu akut solunum sıkıntısı sendromu (ARDS) hastalarında alternatif bir kurtarıcı mod olarak düşünülmektedir (9). APRV'nin ARDS tedavisinde klasik ventilasyona kıyasla hastanın hemodinamik durumunu kötüleştirmeksizin daha düşük tepe basıncı, daha iyi oksijenasyon, daha az dolaşımsal kayıp ve daha iyi gaz değişimi sağladığı doğrulanmıştır. Spontan ventilasyonun korunması, en iyi perfüze olan dependant akciğer bölgelerinde öncelikli olarak ventilasyon sağlayarak ventilasyonperfüzyon oranının düzelmesini sağlar (10). Beyin ölümü gelişmesi olası, organ koruyucu tedavilerin oldukça önemli olduğu, kötü prognozlu olgularda akciğerlerin korunması için uygulanabilecek tedaviler arasında APRV mod da düşünülebilir. Karbonmonoksit zehirlenmelerinde yine yüksek konsantrasyonlarda oksijen verilebilmesi ve kapalı alveollerin açılmasına (recruitment) olanak sağlayabileceği için kullanımı avantajlı olabilir. CO'ya maruz kalmış donörlerden yapılan başarılı böbrek, kalp, akciğer, karaciğer ve pankreas nakilleri raporlanmışır (5,11-15). CO kan damarlarını gevşetir, platelet agregasyonunun inhibisyonu ve fibrinolizis artışılla antitrombotik etki yapar. Karbonmonoksit iskemi/reperfüzyon hasarını ve inflamatuvar cevabı azaltmaktadır. Hayvan modellerindeki çalışmalarda da donörlerde yapılan karbonmonoksit tedavisiyle greft fonksiyonlarında iyileşme görülmüştür. Karbonmonoksit inhale eden donörlerin azalmış apoptoz ve artmış endotel hücre ömrü sayesinde daha iyi greft fonksiyonu gösterdiği de bildirilmiştir (6). Bizim olgumuzda hastamız karaciğer ve böbrek donörü oldu ancak kalp ve akciğer için uygun alıc bulunamadığından donasyon yapılamadı.

\section{SONUÇ}

CO intoksikasyonunda pulmoner tutulumda ARDS tablosuyla nadiren karşılaşılır. Bu durumda yoğun bakım ihtiyacı gelişen ağır olgularda APRV mod ile uygulanan mekanik ventilasyon başarılı sonuçlar verebilir, artan olgu sayılarıyla deneyimler artırılmalıdır. Ek olarak son yayınlar karbonmonoksit intoksikasyonunda, organ koruyucu bakımın iyi yapıldığı beyin ölümü olgularının organ bekleyen hastalar için transplantasyona uygun olabileceğini ve literatürde başarısız olguların da olmasına rağmen kesin kontrendikasyon olmadığını göstermektedir. 


\section{KAYNAKLAR}

1. Health effects of outdoor air pollution. Committee of the environmental and occupational health assembly of the american thoracic society. Am J Respir Crit Care Med 1996; 153:3-50.

2. Kandiş H, Katırcı Y, Çakır Z, Aslan Ş, Uzkeser M, Bilir Ö. Acil servise karbonmonoksit entoksikasyonu ile başvuran olguların geriye dönük analizi. Akademik Acil Tıp Dergisi 2007;5:21-5.

3. Ernst A, Zibrak JD. Carbonmonoxide poisoning. N Engl J Med 1998;339:1603-8.

4. Piantadosi CA. Carbonmonoxide poisoning. Undersea Hyperb Med 2004;31:167-77.

5. Bentley MJ, Mullen JC, Lopushinsky SR, Modry DL. Successful cardiac transplantation with methanol or carbonmonoxide-poisoned donors. Ann Thorac Surg 2001;71:1194-7.

6. Fujisaki $N$, Nakao A, Osako $T$, Nishimura $T$, Yamada $T$, Kohama K, et al. Can carbonmonoxide-poisoned victims be organ donors? Medical Gas Research 2014;4:13.

7. Martin-Suarez S, Mikus E, Pilato E, Bacchini M, Savini C, Grigioni $F$, et al. Cardiac transplantation from a carbonmonoxide intoxicated donor. Transplant Proc 2008;40:1563-5.

8. Dries DJ, Marini JJ. Airway pressure release ventilation. J Burn Care Res 2009;30:929-36.
9. Stock MC, Downs JB, Frolicher DA. Airway pressure release ventilation. Crit Care Med 1987; 15:462-6.

10. Froese AB, Bryan AC. Effects of anesthesia and paralysis on diaphragmatic mechanics in man. Anesthesiology 1974;41:242-55.

11. Bojakowski K, Gaciong Z, Grochowiecki T, Szmidt J. Carbonmonoxide may reduce ischemia reperfusion injury: a case report of complicated kidney transplantation from a carbonmonoxide poisoned donor. Transplant Proc 2007;39:2928-9.

12. Koerner MM, Tenderich G, Minami K, Morshuis M, Mirow $N$, Arusoglu L, et al. Extended donor criteria: use of cardiac allografts after carbonmonoxide poisoning. Transplantation 1997;63:1358-60.

13. Luckraz H, Tsui SS, Parameshwar J, Wallwork J, Large SR. Improved outcome with organs from carbonmonoxide poisoned donors for intrathoracic transplantation. Ann Thorac Surg 2001;72:709-13.

14. Shennib H, Adoumie R, Fraser R. Successful transplantation of a lung allograft from a carbonmonoxide-poisoning victim. J Heart Lung Transplant 1992;11(1 Pt 1):68-71.

15. Verran D, Chui A, Painter D, Shun A, Dorney S, McCaughan $G$, et al. Use of liver allografts from carbonmonoxide poisoned cadaveric donors. Transplantation 1996;62:15145. 